\title{
Effects of monensin on glucose metabolism in transition dairy cows
}

\author{
X. Markantonatos ${ }^{1}$ and G. A. Varga \\ Department of Animal Sciences, The Pennsylvania State University, University Park 16802
}

\begin{abstract}
Eight multiparous periparturient Holstein cows fitted with ruminal cannula were used in a split plot design to evaluate the effects of monensin on plasma glucose metabolism. Diets were top-dressed daily with $0 \mathrm{mg} /$ cow of monensin (control) or $300 \mathrm{mg} / \mathrm{cow}$ of monensin (MON) both pre- and postpartum. Plasma glucose kinetic parameters on $\mathrm{d}-13 \pm 2.0$ and $19 \pm 1.6$ relative to parturition were determined by using stable isotopes. Na-1- ${ }^{13} \mathrm{C}_{3}$-Propionate (labeled propionate) was infused into the rumen to measure glucose synthesis originating from ruminal propionate, and $\mathrm{U}_{-}^{13} \mathrm{C}$-glucose (labeled glucose) was injected into the jugular vein to determine total glucose kinetics. A sampling period of $480 \mathrm{~min}$ following labeled glucose injection was implemented. A compartmental analysis was employed to determine steady state glucose kinetic parameters. To develop a steady state glucose model, the Windows version of SAAM software (WinSAAM) was used. A 4-compartment model was adequate to comprehensively describe plasma glucose metabolism. The main model compartments consisted of propionate and plasma glucose. The time frame of the 480-min sampling period post-tracer glucose infusion allowed accurate quantification of glucose metabolism. The model estimated that glucose input from sources other than ruminal propionate decreased with MON, from 2.26 to $1.09 \mathrm{~g} / \mathrm{min}$ postpartum. Gluconeogenesis, expressed as the propionate contribution to the plasma glucose pool, increased in cows fed MON (22 vs. 31\%), whereas glucose oxidation, expressed as the glucose disposal rate, significantly decreased ( 1.67 vs. $0.92 \mathrm{~g} / \mathrm{min}$ ). In conclusion, MON may improve the energy status of transition cows by (1) improving the efficiency of propionate to produce glucose and (2) decreasing glucose oxidation in body tissues.
\end{abstract}

Key words: monensin, transition cow, glucose metabolism, compartmental analysis

Received September 16, 2016.

Accepted July 24, 2017.

${ }^{1}$ Corresponding author: xmarkantonatos@gmail.com

\section{INTRODUCTION}

The most crucial period for dairy cows is the physiological period from late pregnancy to the onset of lactation, when the demand for energy increases to meet the requirements for the fetus and milk production (Bell, 1995). For a cow to meet the increased demands of lactation, energy may be mobilized from stores such as adipose tissue. Increases in the mobilization of adipose tissue will increase the concentration of fatty acids in the blood levels, thus predisposing cows to metabolic disorders such as ketosis and fatty liver (Duffield et al., 1998; Ospina et al., 2010). Greater glucose supply may increase insulin, which in turn helps to decrease body fat mobilization and circulating fatty acids (Christensen et al., 1997; Rabelo et al., 2005). Energy supply could be increased by various feeding strategies, including feeding more fermentable sources of carbohydrates, administering propylene glycol prepartum, and feeding glycerol (Grummer, 1995) and monensin (McCarthy et al., 2015b,c). Feeding more fermentable carbohydrates prepartum may increase the capacity for VFA absorption by the rumen epithelium (Bannink et al., 2011), acclimate the microbial population to lactation diets, and reduce lipolysis by increasing glucogenic precursors to the liver (Grummer, 1995). In transition cows, propylene glycol enhances energy status by increasing plasma glucose and insulin and decreasing fatty acids and BHB (Nielsen and Ingvartsen, 2004). Monensin improves the energy status of the transition cow by altering VFA production toward more propionate production (McGuffey et al., 2001). An enhanced production of propionate in the rumen can increase glucose availability to the host through gluconeogenesis. Glucose derived from propionate produced in the rumen constitutes a major portion (24-61\%) of total energy production (Young, 1977; Bergman, 1990). However, it is debatable as to whether an increase in propionate production may reflect a proportional increase in the contribution of propionate to the plasma glucose pool (Young, 1977). In early lactation, propionate removal by the liver has been shown to increase by $69 \%$ (Reynolds et al., 2003). McCarthy et al. (2015c) reported that the liver capacity to convert propionate to glucose ranges between 85 and $126 \%$ of prepartum values on $\mathrm{d} 1$ and 
21 after parturition. An increased hepatic propionate metabolism in early lactation may increase (McCarthy et al., 2015c) or may not affect (Larsen and Kristensen, 2009a,b) hepatic gluconeogenesis. McCarthy et al. (2015b) demonstrated increased propensity of the liver to convert propionate to glucose in cows in early lactation through an increase in the ratio of glucose to $\mathrm{CO}_{2}$ when monensin was fed during early lactation.

Various methods have been proposed to study glucose metabolism, such as in vivo measurements of splanchnic metabolism (Kristensen and Harmon, 2004), in vitro methods with biopsied liver slices (McCarthy et al., 2015b,c), and kinetic analysis of glucose metabolism (Arieli et al., 2001). Kinetic research of glucose has involved dilution studies with the use of radioisotopes, mainly ${ }^{14} \mathrm{C},{ }^{3} \mathrm{H}$, (Leng and Brett, 1966; Van Maanen et al., 1978), or ${ }^{13} \mathrm{C}$ stable isotopes (Breves et al., 1993; Arieli et al., 2001; Martin et al., 2001). All of the above kinetic studies were conducted with sheep, steers, or lactating cows, except for Arieli et al. (2001), which was with transition dairy cows. Although many studies have evaluated VFA metabolism in the rumen and gluconeogenesis (Van Maanen et al., 1978; Armentano and Young, 1983; Nolan et al., 2014), only the studies by Van Maanen et al. (1978) and Armentano and Young (1983) examined the effect of monensin on propionate and glucose metabolism using compartmental analysis in steers. Arieli et al. (2001) studied glucose metabolism of transition cows provided monensin prepartum, employing compartmental analysis by a simulation model to describe glucose kinetic parameters. In that study (Arieli et al., 2001), fractional catabolic rate and glucose disposal rate (GDR) were reduced, with an increase in the plasma glucose pool, indicating an improvement in the energetic status of transition cows with monensin. Currently, information is lacking in the literature concerning the effects of monensin fed through the transition period on the kinetic parameters of gluconeogenesis.

Our study was conducted to investigate and quantify the effects of monensin administration fed continuously through the transition period on pre- and postpartum glucose kinetics. We hypothesized that monensin inclusion in the diet would increase fractional conversion of substrates to glucose and the effects would depend upon the reproductive stage of the cow.

\section{MATERIALS AND METHODS}

\section{Experimental Design and Treatment Allocation}

Eight rumen-cannulated multiparous periparturient Holstein cows were used in a split plot design to mea- sure the effects of monensin on metabolism of plasma glucose during the transition period (i.e., prepartum vs. postpartum). The main emphasis was to determine the kinetic parameters of glucose and the production rate of propionate during the periparturient period in dairy cows. Cows were randomly assigned to treatments on $\mathrm{d}$ 30 relative to expected parturition with randomization restricted to balancing for previous 305-d lactation mature equivalent milk production and BCS. Cows were also blocked according to the expected calving date. The 2 treatments were 0 (control; CON) or $300 \mathrm{mg}$ of monensin/cow per day (MON; Elanco Animal Health, Greenfield, IN). Four cows $(\mathrm{n}=4)$ were assigned to each treatment. Cow in the design was the whole plot, treatment was a whole plot factor, and reproductive stage (prepartum or postpartum) was used as the subplot factor.

All procedures associated with the experimental protocol were in accordance with the Pennsylvania State University Institutional Animal Care and Use Committee.

\section{Feeding and Management of Cows}

Cows were dried off on d 60 before expected parturition and moved to a ventilated tiestall facility where they were housed until d 56 postpartum. Approximately on d 1 before calving, cows were moved with their feed to the maternity barn; within $1 \mathrm{~d}$ after calving they returned to the tiestall facility. Cows had free access to water at all times. All cows were individually fed ad libitum a TMR and switched to a lactation TMR (Table 1) after parturition. They were fed once a day at approximately $0800 \mathrm{~h}$.

For the treatment cows, monensin was incorporated into a pellet containing $170.5 \mathrm{~g}$ of distiller's grain as the carrier. The daily dose of monensin was preweighed and labeled for the appropriate cow and date, and topdressed beginning on d 30 before the expected calving date. To adapt cows to monensin, $85 \mathrm{~g} / \mathrm{d}$ was fed for the first $3 \mathrm{~d}$ of monensin supplementation.

\section{Blood Sampling}

Blood samples for plasma and serum were collected via venipuncture of the coccygeal vein into evacuated tubes (Becton Dickinson and Co., Rutherford, NJ). Blood was sampled approximately $2 \mathrm{~h}$ postfeeding on the same day of each week starting 4 wk before calving through $8 \mathrm{wk}$, postcalving. Blood $(\sim 7 \mathrm{~mL})$ for plasma glucose determination was collected in tubes containing sodium heparin and $4 \%$ sodium fluoride. All other tubes for other plasma and serum analyses contained 
only sodium heparin. All blood samples were placed in an ice container and followed by centrifugation at $4^{\circ} \mathrm{C}$ at $3,300 \times \mathrm{g}$ for $15 \mathrm{~min}$ within $1 \mathrm{~h}$ of collection. Serum tubes were allowed to stand at room temperature for approximately $1 \mathrm{~h}$ for clotting before being centrifuged at room temperature at $2,200 \times g$ for $20 \mathrm{~min}$. Plasma and serum were stored at $-20^{\circ} \mathrm{C}$ until analyzed.

Table 1. Ingredients and chemical composition of prepartum and postpartum diets fed to periparturient Holstein cows

\begin{tabular}{|c|c|c|}
\hline \multirow[b]{2}{*}{ Item } & \multicolumn{2}{|c|}{ Diet $^{1}$} \\
\hline & Prepartum & Postpartum \\
\hline \multicolumn{3}{|l|}{ Ingredient, $\%$ of $\mathrm{DM}$} \\
\hline Alfalfa haylage & - & 14.5 \\
\hline Corn silage & 30.2 & 24.1 \\
\hline Cottonseed hulls & 12 & - \\
\hline Ground corn grain & 13.9 & 14.8 \\
\hline Wheat straw & 3.6 & - \\
\hline Wheat middlings & 2.37 & - \\
\hline Soyhulls & 15.5 & - \\
\hline Alfalfa hay & 8.1 & 9.4 \\
\hline Soybean meal, $48 \%$ of $\mathrm{CP}$ & 7.6 & - \\
\hline Soybeans, cooked & - & 6.4 \\
\hline Canola meal (solvent) & - & 2.7 \\
\hline Cookie meal & - & 6.5 \\
\hline Sugar (dextrose) & - & 3.6 \\
\hline Vitamin and mineral mixture ${ }^{2}$ & 3.8 & - \\
\hline Liquid molasses & 2.5 & - \\
\hline Urea & 0.28 & - \\
\hline Sodium bentonite & 0.24 & 0.36 \\
\hline Bicarbonate & - & 0.7 \\
\hline Grain mixture $^{3}$ & - & 17.2 \\
\hline \multicolumn{3}{|l|}{$\begin{array}{l}\text { Chemical composition (\% of DM, } \\
\text { unless noted) }\end{array}$} \\
\hline $\mathrm{DM}$ & 59.6 & 54.7 \\
\hline $\mathrm{CP}$ & 12.7 & 17.2 \\
\hline Soluble CP (\% of CP) & 35.0 & 41.0 \\
\hline $\mathrm{ADF}$ & 34.8 & 21.8 \\
\hline NDF & 49.7 & 33.6 \\
\hline $\mathrm{NFC}^{4}$ & 32.6 & 37.7 \\
\hline Fat & 2.8 & 5.2 \\
\hline $\mathrm{NE}_{\mathrm{L}}^{5}(\mathrm{Mcal} / \mathrm{kg})$ & 1.45 & 1.75 \\
\hline $\mathrm{Ca}$ & 0.51 & 0.85 \\
\hline $\mathrm{P}$ & 0.36 & 0.42 \\
\hline $\mathrm{Mg}$ & 0.32 & 0.30 \\
\hline $\mathrm{K}$ & 1.2 & 1.4 \\
\hline
\end{tabular}

${ }^{1}$ Number of composited samples of prepartum and postpartum diets; $\mathrm{n}=2$.

${ }^{2}$ Prepartum vitamin and mineral mix contained ( $\%$ DM, unless noted): $90.28 \mathrm{DM}, 2.66 \mathrm{Ca}, 4.21 \mathrm{Cl}, 3.83 \mathrm{Mg}, 2.9 \mathrm{Na}, 1.10 \mathrm{~S}, 0.56 \mathrm{P}, 304 \mathrm{mg} /$ $\mathrm{kg}$ of $\mathrm{Cu}, 889 \mathrm{mg} / \mathrm{kg}$ of $\mathrm{Mn}, 199 \mathrm{mg} / \mathrm{kg}$ of Fe, $8.08 \mathrm{mg} / \mathrm{kg}$ of Se, $158,400 \mathrm{IU} / \mathrm{kg}$ of vitamin $\mathrm{A}, 39,600 \mathrm{IU} / \mathrm{kg}$ of vitamin $\mathrm{D}, 4,378.0 \mathrm{IU} /$ $\mathrm{kg}$ of vitamin $\mathrm{E}$.

${ }^{3}$ Grain mix contained (\% DM), unless noted: 38.6 distillers grain, 38.6 wheat middlings, 10.1 Turbo Meal (heat-treated soy protein; J. L. Moyer \& Sons Inc., Turbotville, PA), 3,85 fish meal, 5.1 aragonite, 3.35 mineral and vitamin mix (\% DM: $2.64 \mathrm{Ca}, 0.96 \mathrm{P}, 1.0 \mathrm{Mg}, 1.5 \mathrm{~K}, 0.38$ $\mathrm{S}, 312.8 \mathrm{mg} / \mathrm{kg}$ of $\mathrm{Mn}, 95.8 \mathrm{mg} / \mathrm{kg}$ of $\mathrm{Cu}, 343.8 \mathrm{mg} / \mathrm{kg}$ of $\mathrm{Zn}, 202.4$ $\mathrm{mg} / \mathrm{kg}$ of Fe, $5.13 \mathrm{mg} / \mathrm{kg}$ of Se, 20,262.0 IU $/ \mathrm{kg}$ of vitamin $\mathrm{A}, 5,021.5$ $\mathrm{IU} / \mathrm{kg}$ of vitamin $\mathrm{D}, 148.0 \mathrm{IU} / \mathrm{kg}$ of vitamin $\mathrm{E}$ ).

${ }^{4}$ Nonfiber carbohydrates percentage $=100-(\% \mathrm{NDF}+\% \mathrm{CP}+\%$ Fat $+\%$ Ash).

${ }^{5}$ Calculated according to NRC (2001).

\section{Milk, Feed, and Animal Measurements}

Milk samples were collected weekly, at 2 consecutive milkings (morning and evening), beginning on d 4 after parturition and ending on d 56 postcalving. Milk samples were collected into 4 tubes ( 2 for morning and 2 for evening milking) containing the preservative 2-bromo2-nitropropane-1,3-diol and analyzed individually. One tube from each milking was used for milk composition analyses. If one or both milk samples were missed, both samplings (morning and evening) were repeated on the next sampling day.

Cows were scored for BCS on a scale of 1 to 5 with quarter-point increments (1 being emaciated and 5 being obese) and evaluated once per week by a team of 3 individuals (Wildman et al., 1982); the average was the score of that week. Cows were also weighed weekly for BW measurement on the same day and time.

Samples of each TMR were collected every morning before feeding. At the end of the week, daily samples were composited to make up a weekly sample. Prepartum and postpartum weekly TMR samples were dried in a $55^{\circ} \mathrm{C}$ forced-air oven for $2 \mathrm{~d}$ for DM determination and then ground in a Wiley mill (A. H. Thomas, Philadelphia, PA) to pass through a 1-mm screen. Samples of ground TMR were composited by period and analyzed for chemical compounds (Table 1). Analytical DM was determined by drying the TMR at $135^{\circ} \mathrm{C}$ for $3 \mathrm{~h}$ (method 930.15; AOAC International, 2005). Nitrogen was determined by combustion (method 990.03; AOAC International, 2005; Leco FP-528 Combustion Analyzer; Leco Instruments Inc., St. Joseph, MI). Soluble $\mathrm{CP}$ was determined using a borate-sodium phosphate buffer procedure (Roe et al., 1990). Acid detergent fiber (inclusive residual ash) and NDF (inclusive residual ash) were determined using the ANKOM A200 Filter Bag Technique (ANKOM Technology, Macedon, NY) according to Van Soest et al. (1991), with heat-stable amylase but without the use of sodium sulfite in the NDF procedure. Fat was determined by using a Soxtec (Tecator Soxtec System HT 1043 Extraction unit; Eden Prairie, MN; method 2003.05; AOAC International, 2005). Minerals were determined using a Perkin Elmer 3300 XL and 5300 DV ICP (Shelton, CT) with modifications (method 985.01; AOAC Itnernational, 2005).

\section{Experimental Kinetic Protocol}

For cows to achieve as close to metabolic steady-state conditions as possible, a frequent feeding schedule was implemented. Starting on $3 \mathrm{~d}$ before the start of the experiment, cows were fed 4 equal sized meals at 6 -h intervals for $2 \mathrm{~d}$, and then they were fed equal sized meals at 2 -h intervals. The feedings at 2 -h intervals continued 
throughout the day of the application of the propionate and glucose tracers. Just before tracer administration, water availability was terminated to prevent sudden changes in water volume in the rumen and then was resumed right after the 320-min sampling period of rumen sampling. Experiments were carried out on d $13 \pm$ 2.0 before calving and on d $19 \pm 1.6$ after parturition.

Kinetic parameters of propionate in the rumen were measured using Na-1- ${ }^{13} \mathrm{C}$-propionate (labeled propionate; Isotec Inc., Miamisburg, OH; 99 atom percent) infused into the rumen as a bolus at time zero $\left(\mathbf{t}_{\mathbf{0}}\right)$ employing a single infusion (i.e., bolus dose). All cows received $19.29 \mathrm{~g}$ ( $12 \%$ of total propionate pool size) of labeled propionate. Before tracer administration, a background sample was collected at $-30,-20$, and -10 min relative to infusion time. At $\mathrm{t}_{0}$, the tracer was infused into the rumen by a funnel probe, ensuring that the tracer was evenly distributed in the rumen. Following tracer infusion, rumen contents were thoroughly mixed with the tracer by hand for 2 min before being withdrawn from 9 different rumen sites at 5, 10, 15, $25,35,45,60,75,90,110,130,150,170,205,230,260$, 290 , and $320 \mathrm{~min}$ after infusion and being composited. To help maintain the rumen as anaerobic as possible, a mixture of $\mathrm{N}_{2}$ and $\mathrm{CO}_{2}[1: 1(\mathrm{vol} / \mathrm{vol})]$ was released slowly into the headspace of the rumen while the cannula was uncapped for sampling.

\section{Glucose Kinetics}

Catheterization of Cows. The day before glucose kinetics sampling, cows were catheterized via the jugular vein. A sterile catheter was inserted approximately $65 \mathrm{~cm}$ into the jugular vein through a 12 -gauge needle. The catheter was $55 \mathrm{~cm}$ in length, made from $1.02 \mathrm{~mm}$ i.d. and $1.78 \mathrm{~mm}$ o.d. Tygon microbore tubing (Fisher Scientific Co., Pittsburgh, PA), and gas-sterilized before use. Immediately following insertion, the needle was removed from the catheter and a 19-gauge tubing was secured to the end of the catheter using plastic ties.

Day of Sampling. On the day before sampling, cows were fed at 2-h intervals every even hour, so that on the day of sampling cows were fed at 0800 , 1000, 1200, 1400, and $1600 \mathrm{~h}$. At $0800 \mathrm{~h}, 45 \mathrm{mg}$ of labeled glucose (100.01 $\pm 0.05 \%$, Cambridge Isotope Laboratories, Andover, MA) in $10 \mathrm{~mL}$ of sterile saline was injected through the injection cap using a $12-\mathrm{mL}$ syringe and a 20-gauge needle. Immediately following, $7 \mathrm{~mL}$ of sterile saline with heparin was injected to flush the catheter. Samples were collected $(25 \mathrm{~mL})$ at $-10,5$, $10,15,20,25,30,35,40,50,60,75,90,110,140,170$, $205,260,325,395$, and 480 min relative to the labeled glucose injection (Arieli et al., 2001). Samples were im- mediately put on ice. Samples were centrifuged at 3,300 $\times \mathrm{g}$ for $20 \mathrm{~min}$ at room temperature within $30 \mathrm{~min}$ of collection, and the supernatant was divided into equal aliquots for total plasma and isotopic glucose analysis.

Analytical Procedures. Weekly blood plasma samples were analyzed for glucose (Sigma Glucose Kit 510-A, Sigma Chemical Co., St. Louis, MO), BUN [Diacetylmonoxime Urea Nitrogen method (Kit No. 0580 250); Stanbio Laboratory, Boerne, TX], and fatty acids (Wako NEFA C, Kit No. 990, 75401; Wako Chemicals, Richmond, VA). Serum insulin was determined using an RIA kit (Coat-A-Count, Insulin kit number TK1NX; Diagnostic Products Corp., Los Angeles, CA).

Plasma samples collected during the glucose kinetic sampling period were analyzed for ${ }^{13} \mathrm{C}$-glucose in total plasma glucose (IRMS - Hewlett Packard 5989A isotope ratio mass spectrometry, Metabolic Solutions Inc., Merrimack, NH). The abundance of labeled glucose in the blood samples was determined as atom percent excess (APE; Putnam et al., 1999).

Calculations of ${ }^{13}$ C-Glucose and ${ }^{13}$ C-Propionate Isotopic Enrichments. The concentration of labeled glucose was determined as delta $(\Delta)$ values per milliliter relative to a known isotopic standard (sucrose obtained from the International Atomic Energy Agency, Vienna, Austria). Delta values were converted to APE values, or the percentage of the carbons in glucose that are ${ }^{13} \mathrm{C}$ according to the following equation (Putnam et al., 1999):

$$
\mathrm{APE}=100 /\left\{\left[\left(\Delta^{13} \mathrm{C} / 1,000\right)+1\right] \times 0.0112372+1\right\} .
$$

In turn, each time point after the labeled glucose injection was corrected for the background (sample taken 10 min before labeled glucose injection) enrichment. The APE, which represents the enrichment of the glucose molecule with ${ }^{13} \mathrm{C}$ above background, was then used to calculate enriched glucose concentration as well as plasma glucose parameters, such as plasma glucose pool size, glucose dispersion volume, and glucose clearance rate at a given time $t$.

${ }^{13} \mathrm{C}$-Propionate isotopic abundance was calculated as described by Markantonatos et al. (2009). Isotopic abundances of labeled propionate were expressed as tracer/(tracer + tracee) (TTR) and corrected for skewness as described by Wolfe (1992). The notation F is used to express the TTR:

$$
\mathrm{F}=100 \times\left[\left(\frac{\alpha_{1}}{\beta_{1}}-\frac{\alpha_{2}}{\beta_{2}}\right) \times \frac{1}{1+\mathrm{A} \times \eta}\right],
$$


where $\alpha_{1}=\frac{Q_{2}}{Q_{1}+Q_{2}}$ (of the tracer sample), $\alpha_{2}=\frac{Q_{2}}{Q_{1}+Q_{2}}$ (of the background sample), $\beta_{1}=100-\alpha_{1}$, and $\beta_{2}=100-\alpha_{2} \cdot \frac{Q_{2}}{Q_{1}+Q_{2}}$ is the value reported by the GCmass selective detector for ${ }^{13} \mathrm{C}$ enrichment, $\mathrm{A}$ is the natural isotopic abundance of the labeled carbon (natural isotopic abundance of ${ }^{13} \mathrm{C}$ is 0.0111 ), and $\eta$ is the number of carbon atoms labeled with the stable isotope (in our case $\eta=1 ; 1$ carbon atom labeled at first position - carboxylic domain in the VFA molecule). Values of $\frac{Q_{2}}{Q_{1}+Q_{2}}$ for the background samples were averaged from the samples taken before label administration and were used to calculate the $\mathrm{F}$ value for all samples.

\section{Description of the Propionate-Glucose Model}

A 4-compartment model was constructed with the assumptions (a) cows were in a steady-state condition with respect to ruminal propionate and plasma glucose; (b) no re-entry of label back into the rumen (France and Dijkstra, 2005); (c) no exchange of any single labeled ${ }^{13} \mathrm{C}$ or other compounds during the kinetics studies (Markantonatos et al., 2009); (d) propionate acted as a single pool (it does not exchange ${ }^{13} \mathrm{C}$ with the other major VFA; i.e., acetate and butyrate; Bergman et al., 1965; Leng and Leonard, 1965); and (e) 1 mol of glucose is formed from 2 mol of propionate, and all carbon atoms within these $2 \mathrm{~mol}$ of propionate appear in the formed glucose (Leng and Leonard, 1965). The model described the kinetics of both labeled propionate infused in the rumen and labeled glucose injected through the jugular vein following bolus infusion of labeled propionate and instant injection of labeled glucose at $t_{0}$. Kinetic curves of $\mathrm{F}$ values of tracers versus time were analyzed by WinSAAM, a Windows-based version of the Simulation, Analysis, and Modeling (SAAM) Software for the analysis of data (Stefanovski et al., 2003). The software fitted the data by an iterative process, modifying the adjustable parameters until no further decline in the sum of squares of the differences of observed and calculated values was observed. During best fit, the software calculated statistical uncertainty for the model parameters in terms of fractional standard deviation $(\mathbf{F S D}=\mathrm{SD} /$ mean $)$.

Compartment in the described model has the same meaning as pool; thus, both terms are used to describe the same entity. A schematic representation of the model is presented in Figure 1. The main ruminal compartment of the model was propionate, which also was the sampling site of propionate. During the iteration process of solving the model, values were best fitted only if propionate carbons were forced to pass through another space or compartment before they entered the plasma glucose. For modeling and simplicity purposes, that space was named the delay compartment (DC; Figure 1).

The glucose system of the model consists of 2 main compartments: plasma glucose (GIP) and secondary glucose (GlS). The GlS compartment represents all glucose pools in the body except plasma glucose, and it is a putative pool that rapidly exchanges glucose with GIP. Inputs in GIP are glucose molecules from exogenous labeled glucose and glucose molecules that are synthesized from ruminal propionate. Isotopic enrichments of propionate and glucose were analyzed employing a weighted nonlinear regression analysis.

\section{Mathematical Expression of the Model}

Model Parameters. The model consisted of 8 adjustable, 6 dependent, and 1 fixed parameters. The fixed parameter was the flux of glucose molecules from GIP to GlS during labeled glucose injection; it was calculated to be equal to $0.01385 \mathrm{~mol}$ of glucose $/ \mathrm{min}$ (Arieli et al., 2001). Fluxes were defined in the model as fractional transfer rates $\left(\mathrm{L}_{\mathrm{i}, \mathrm{j}}\right.$; i.e., the fraction of the donor pool that flows at this rate per unit time to the recipient pool). These parameters define the kinetics of the tracer, calculating the fluxes of the tracer out of $\left(\mathrm{L}_{0, \mathrm{j}}\right)$ and between pools $\left(\mathrm{L}_{\mathrm{i}, \mathrm{j}} ; \mathrm{i}=\right.$ the recipient pool, and $\mathrm{j}=$ the donor pool); they are expressed in terms of percent of the tracer in the whole molecule of the tracer plus the tracee per unit time $(\% / \mathrm{min})$. Thus, the product of such transfer by the donor pool is the absolute flux $\left(\mathrm{R}_{\mathrm{i}, \mathrm{j}}\right)$ of the tracee in terms of grams per minute (Figure 1).

Functions to Calculate Carbon Exchanges. Calculation of the incorporation of propionate into plasma glucose at any given time is described as

$$
\mathrm{G}_{(\mathrm{Pr} \rightarrow \mathrm{Gl})}=\left(\mathrm{F}_{1} / 6+\mathrm{F}_{2}\right) / \mathrm{M}_{(\mathrm{GlP})}
$$

where $\mathrm{G}_{(\mathrm{Pr} \rightarrow \mathrm{Gl})}$ is the incorporation of ruminal propionate to glucose, $\mathrm{F}_{1}$ is the amount of ${ }^{13} \mathrm{C}$-propionate in GIP at a given time $t, F_{2}$ is the amount of ${ }^{13} \mathrm{C}$-glucose in GIP at a given time $t$ during labeled glucose injection, and $\mathrm{M}_{(\mathrm{GlP})}$ is the mass (g) of GlP. $\mathrm{F}_{1}$ is divided by 6 because it is assumed that all carbon atoms of propionate appear in the formed glucose.

With the assumption that the GIP and GIS pools are in a steady state, the system consisting of those pools is considered as a closed system in equilibrium. Consequently, the ratio of these glucose pools is equal to the ratio of the fractional transfer rates of glucose 
(A)

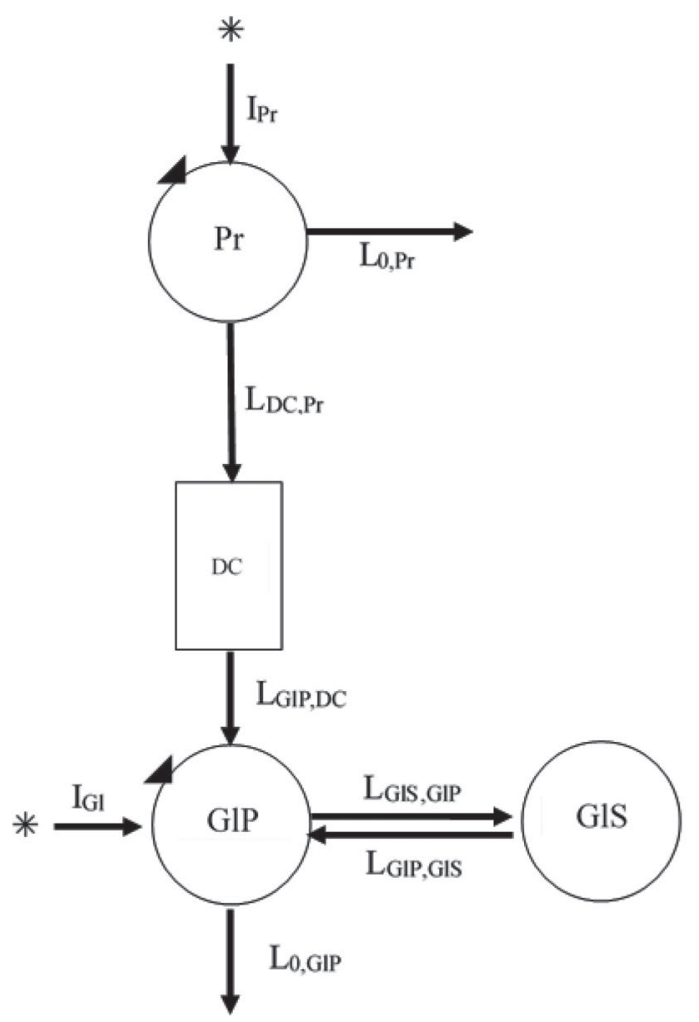

(B)

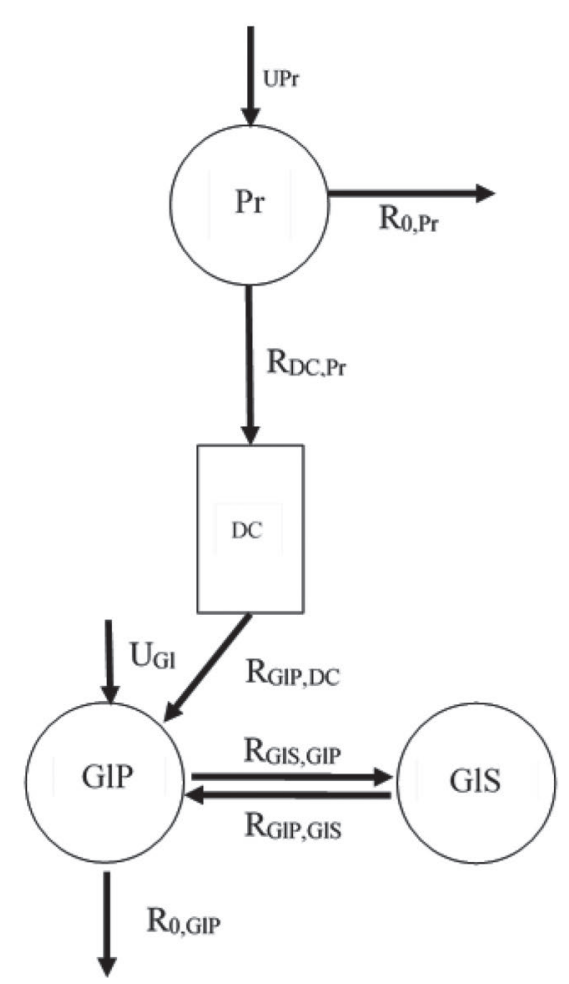

Figure 1. An integrated-interchanging 4-compartment model of ruminal propionate (Pr), and plasma glucose (Gl) metabolism: (A) tracer system and (B) tracee system. DC = delay compartment for carbon atoms of propionate before they enter plasma glucose; GlP $=$ plasma glucose or primary glucose pool, which accepts glucose molecules from both exogenous labeled glucose and glucose molecules that are synthesized from ruminal propionate; GlS = glucose pool, which accepts glucose molecules from plasma glucose; $\mathrm{I}_{\mathrm{Pr}}=$ the site of tracer propionate infusion; $\mathrm{I}_{\mathrm{Gl}}=$ the site of tracer glucose tracer injection; $\mathrm{L}=$ the fractional transfer rate of tracer molecules $\left(\mathrm{e} . \mathrm{g} ., \mathrm{L}_{\mathrm{GIP}, \mathrm{DC}}\right.$ is the fractional rate of tracer molecules from delay compartment to plasma glucose); $0=$ outside space of propionate and glucose pools; $\mathrm{R}=$ the absolute transfer rate of the tracee propionate or glucose; $\mathrm{U}_{\mathrm{Pr}}=$ the entry rate of dietary propionate; $\mathrm{U}_{\mathrm{Gl}}=$ the entry rate of glucose coming from other sources than propionate; an asterisk $\left(^{*}\right.$ ) represents the doses of propionate and glucose tracers; closed triangle $(\mathbf{\Delta})$ represents sampling sites of tracer propionate and glucose. The scheme assumes no re-entry of label into the system.

molecules between the 2 pools. Therefore, the relationship is described by the equation (Arieli et al., 2001):

$$
\mathrm{M}_{\mathrm{GIS}} / \mathrm{M}_{\mathrm{GIP}}=\mathrm{L}_{(\mathrm{GIP}, \mathrm{GIS})} / \mathrm{L}_{(\mathrm{GIS}, \mathrm{GLP})},
$$

where $\mathrm{M}_{\mathrm{GIS}}(\mathrm{g})$ is the mass of GlS, $\mathrm{M}_{\mathrm{GIP}}(\mathrm{g})$ is the mass of GlP, and $\mathrm{L}_{(\mathrm{GIP}, \mathrm{GIS})}$ is the fractional transfer rate of glucose molecules from GlS to GIP.

\section{Statistical Analysis}

Eight multiparous cows $(\mathrm{n}=8)$ were initially assigned to treatments, but 1 cow was removed from the experiment due to recovery problems from rumen cannulation surgery. Data were analyzed by ANOVA according to a split plot design where cow was the random effect. Calculated values from the simulation model of glucose kinetic parameters were analyzed using a statistical model that included sampling time points, treatment, reproductive stage, and possible interactions as fixed factors. Repeated measures of data, such as glucose concentration and pools, were analyzed using the PROC MIXED procedure of SAS (Littell et al., 1996) to examine the effect of treatment (CON vs. MON) within the reproductive stage as well as the effect of the reproductive stage. The statistical model used for the effect of treatment within the reproductive stage included main plot factors of prepartum and postpartum treatments. An ANOVA was conducted for the main effects and their interaction of treatments on kinetic parameters. For repeated measures analysis, the statistical model included treatment, time (sampling time points; min), cow within treatment, and the interaction of treatment with time. For repeated measures concerning time points not equally spaced, such as blood glucose concentration and propionate production over 
the sampling period, the covariate structure for each measurement used was spatial power. This covariate structure resulted in the smallest Akaike information criterion and Schwarz-Bayesian criterion (Littell et al., 1996). Cow within treatment was tested using autoregressive order 1 (ar1). Correlations between observed and calculated values were carried out using Pearson correlation.

Means of DMI, BW, DMI/BW (g/ $\mathrm{kg})$, and BCS changes and blood metabolites, such as fatty acids, BUN, and insulin, were analyzed by using the PROC GLM procedure for SAS [Version 8.0; (SAS Institute, Inc., Cary, NC)]. The statistical model used included main plot factors of prepartum treatment and postpartum treatment. In all statistical analyses, results were presented as least squares means and the accompanying standard error of the mean. The significance level for statistical analyses was set at $P \leq 0.05$.

\section{RESULTS}

\section{Blood Metabolites}

The treatment effect of the reproductive stage on fatty acids and BUN was not significant (data not shown). Prepartum, plasma concentrations of fatty acids averaged 159.3 and $123.5 \pm 18.6 \mu \mathrm{Eq} / \mathrm{L}$ for MON and CON cows, respectively. Postpartum fatty acid concentrations averaged 297.3 and $377.9 \pm 68.4 \mu \mathrm{Eq} / \mathrm{L}$ for MON and CON cows, respectively. Control cows had higher blood fatty acid concentrations from -1 to 1 wk relative to parturition. Due to problems with the insulin analysis, the measured level of insulin postpartum was almost 3 fold lower than normal values; as a consequence, no reliable conclusion could be drawn from insulin data and it was not discussed.

\section{DMI and Milk Parameters}

Daily measurements of DMI were recorded over the entire transition period (from d 30 before parturition to d 56 after parturition). Weekly DMI did not differ between treatments either prepartum or postpartum and averaged 13.4 and $19.5 \mathrm{~kg} / \mathrm{d}$, respectively. Dry matter intake as a percentage of BW was not affected by monensin inclusion in the diet and averaged $3.0 \%$. The DMI 3 d before tracer (steady-state feeding) administration were used for glucose kinetics determination. During the steady state feeding, DMI was lower prepartum in cows provided monensin $(11.4 \pm 1.3$ vs. $17.5 \pm 1.6 \mathrm{~kg} / \mathrm{d}$; MON vs. CON; $P<0.04$ ); however, this difference is probably attributed to the fact that 2 of the cows that were not supplemented with monensin had much higher intakes during steady-state feeding than other times during the experiment (data not shown). On the other hand, DMI during the kinetic experiments, postpartum, did not differ $(P=0.98)$ between treatments, and averaged $19.6 \mathrm{~kg} / \mathrm{d}$.

Milk yield and milk composition did not change in response to monensin supplementation. Milk production for 56 DIM averaged $43.3 \mathrm{~kg} / \mathrm{d}$, milk protein $2.81 \%$ and milk fat content averaged $3.3 \%$.

\section{Model Adjustable Parameters}

Overall results from the model's calculated values for the adjustable parameters were predicted with an accuracy correlation coefficient of 0.91 against the observed values.

Results in Table 2 show that the fractional transfer coefficient $\mathrm{L}_{(\mathrm{DC}, \mathrm{Pr})}$ of the model that describes the flux of ${ }^{13} \mathrm{C}$ from ruminal propionate to the $\mathrm{DC}$ did not differ between CON- and MON-treated cows in either reproductive stage, but it did differ $(P=0.05)$ across the reproductive stage. The fractional rate of glucose $\left(\mathrm{L}_{\mathrm{GIP}, \mathrm{GIS}}\right)$, which expressed the recycling of glucose from the GlS to the GlP, was lower $(P=0.03)$ in CON cows in both physiological stages (2.7 vs. $40 \% / \mathrm{min}$ prepartum, and 3.0 vs. $30 \% / \mathrm{min}$, postpartum, for CON vs. MON). The FSD values for the adjustable parameters were in all cases less than $5 \%$, confirming the prediction accuracy of estimates of the adjustable parameters. The time that glucose molecules spent in GlP before irreversibly leaving the pool (residence time) increased in response to MON inclusion in the diet across the reproductive stage $(P=0.02)$. In contrast, glucose molecules required less time before they departed the GlS pool $(P=0.03)$ in cows fed MON (Table 2$)$.

\section{Glucose Steady-State Estimates}

The average values calculated by the model for blood glucose concentration over the sampling period of 480 min was unaffected by treatment, but we noted a reproductive stage influence $(P=0.0006)$, resulting in a reduction of blood glucose concentration prepartum as opposed to an increase by $25 \%$ postpartum. The GlP as a percent of the total glucose (GlP + GlS) increased $(P=0.017)$ by $87 \%$ in MON-fed cows before parturition and tended to increase by $80 \%(P=0.18)$ after parturition. The increase in size of the GlP ranged from 8 to $165 \%$ for CON and MON cows across the reproductive stage, respectively. The GIS was reduced with MON supplementation by $83 \%$ prepartum. The large reduction in the size of the GIS to cows that received MON (281.2 vs. $47.6 \mathrm{~g}$; CON vs. MON) postpartum was associated with a large standard error (115.4 g) due to high variation of the glucose enrichment data 
for individual cows. Average glucose space of distribution was $150.3 \mathrm{~L}$ across treatments and reproductive stage. Treatment $\times$ reproductive stage interaction and reproductive stage alone increased the size of the glucose space of distribution by 262 and $40 \%$ in CONand MON-supplemented cows, respectively (Table 3). Glucose disposal rate, which corresponds to the fraction of glucose that irreversibly leaves the pool (Leng, 1970), was lower by approximately $55 \%$ (1.67 vs. 0.92 $\mathrm{g} / \mathrm{min}$; CON vs. MON), on average, in cows receiving monensin compared with cows that were not supplemented with monensin across the reproductive stage $(P$ $=0.001$; Table 3 ). In addition, the treatment effects of the reproductive stage and treatment $\times$ reproductive stage were also significant (Table 3 ).

Overall glucose kinetics were calculated by the partial simulation model consisting of compartments GIP (plasma glucose) and GlS (secondary glucose), and they are presented in Figure 1 using as input the ${ }^{13} \mathrm{C}$ glucose coming from injected labeled glucose. Gluconeogenesis, on the other hand, was calculated using as an input the ${ }^{13} \mathrm{C}$-glucose appearing in plasma due to ruminal propionate metabolism. Apart from ruminal propionate, other sources can also contribute to glucose pools. These sources would include (a) dietary starches that escape ruminal fermentation to be digested in the small intestine to glucose (Kristensen and Harmon, 2004), (b) glucose that may come from lactate which is produced from propionate oxidation within the rumen wall (Reynolds et al., 2003), or (c) oxidation of AA from tissue catabolism (Seal and Parker, 1994). Significant effects of the treatment $(P<0.01)$, reproductive stage $(P<0.0001)$, and treatment $\times$ reproductive stage $(P$ $<0.01$ ) were observed in the glucose input rate from sources other than ruminal propionate (Table 1). However, before calving, CON versus MON showed only a tendency $(P=0.16)$ to decrease the glucose input rate with monensin. After calving we observed an almost $50 \%$ decrease in the glucose input rate (2.3 vs. 1.09 $\mathrm{g}$ of glucose/min; CON vs. MON; $P<0.01$; Table 3) when cows were provided monensin. Average input of glucose that did not originate from ruminal propionate was higher postpartum regardless of whether cows received monensin (increased by $220 \%$ ) or not (increased by $176 \%$ ). Glucose disposal rate decreased for cows provided monensin in either reproductive stages (peripartum or postpartum), averaging 0.92 versus $1.67 \mathrm{~g} /$ min for CON versus MON $(P<0.001)$. We also noted a significant effect on this parameter of reproductive stage $(P<0.0001)$ and the interaction of the reproductive stage and treatment $(P<0.01$; Table 3$)$.

Gluconeogenesis due to ruminal propionate is given by 3 parameters: propionate incorporation into plasma glucose (PrIGl; g of glucose/min), propionate contribu- 
MARKANTONATOS AND VARGA

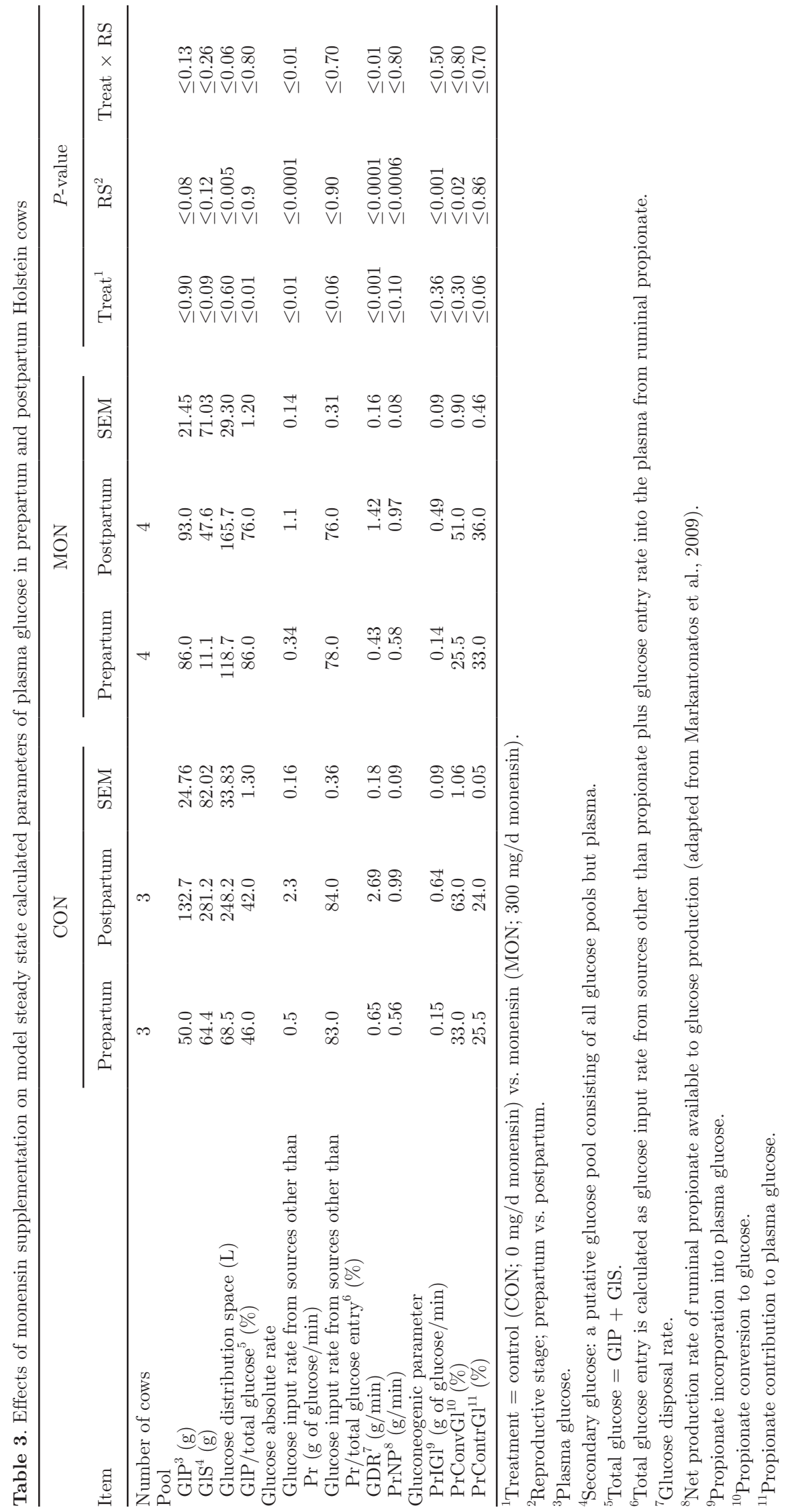


tion to GIP (PrContrGl; \%), and propionate conversion to glucose (PrConvGl; \%). The PrIGl is a value calculated by the model, and PrContrGl is the product of PrIGl divided by GDR; PrConvGl is calculated when PrIGlu is divided by rumen net production rate of propionate. Propionate incorporation to glucose was higher postpartum in both groups of cows, but it was influenced only by the reproductive stage $(P=0.001$; Table 3$)$. The same effect $(P=0.02)$ was observed for PrConvGl, which averaged $33 \%$ in CON cows prepartum and $63 \%$ postpartum, whereas for MON cows these proportions were 25.5 and $51 \%$ prepartum and postpartum, respectively. the PrContrGl expresses how much of the plasma glucose is derived from ruminal propionate and was higher $(P=0.06)$ in MON cows than in CON cows, averaging 25.5 and $24 \%$ in CON cows and 33 and $36 \%$ for cows fed MON, prepartum and postpartum, respectively.

\section{DISCUSSION}

The main objective of our study was to examine the effects of feeding MON throughout the transition period on the availability of gluconeogenic precursors for transition dairy cows. The importance of propionate's contribution to the energy needs of periparturient cows has been reviewed by Larsen and Kristensen (2013). In that review, propionate contribution to glucose metabolism was measured in dairy cows catheterized in major splanchnic vessels, allowing measurements of net nutrient fluxes across the portal-drained viscera and the liver and providing information on the relationship between precursor and product based on arterial-venous differences. Another method of studying propionate metabolism in the liver used biopsied liver slices in vitro (McCarthy et al., 2015b,c). Both methods measure the degree of the precursor converted to product (e.g., propionate to glucose, or glucose to $\mathrm{CO}_{2}$ ) but provide no information about the dynamics of the metabolism (Young, 1977). In contrast, kinetic experiments following dilution studies with isotopic labeled materials could be used to quantify the dynamics and the intermediate state changes of metabolism. The preferred method to quantify the differences in metabolic processes is using kinetic simulation models employing compartmental analysis (Nolan et al., 2014). In the present experiment, we are the first to attempt to quantify gluconeogenesis in transition dairy cows by compartmental analysis.

In studying glucose metabolism, we mainly focused on the determination of gluconeogenesis from ruminal propionate in response to $\mathrm{MON}$; however, an attempt was made to also estimate overall blood glucose ki- netics. A 2-compartment model was used to simulate overall glucose kinetics (Putnam et al., 1999; Schulze et al., 1991; Arieli et al., 2001); the 2 compartments used comprised plasma glucose and secondary glucose, which represent all glucose pools in the body except plasma (Figure 1). The most important parameter for a model to be successful is the initial conditions or the inputs used from the model to simulate glucose kinetics. Inputs are greatly influenced by the metabolic status of the cow and the duration of the sampling period following tracer administration. Arieli et al. (2001) examined the effect of monensin on glucose kinetics in dairy cows during the transition period. They tried to develop steady state conditions by feeding cows $6 \times$ daily $1 \mathrm{~d}$ before and on the day of sampling. This feeding protocol led to a fluctuation in predicted glucose pool sizes, implying that cows were not in steady state conditions. In contrast, experiments with transition cows (Putnam et al., 1999) and steers (Armentano et al., 1984) have demonstrated that feeding $12 \times$ daily is the minimum feeding strategy to achieve steady-state metabolism. In a study with sheep, White et al. (1969) reported a tendency for higher total glucose production rates and irreversible loss in sheep fed once daily compared with sheep fed hourly. White et al. (1969) suggested that estimations of glucose kinetics are valid only if a relative glucose steady state has been achieved, in agreement with later studies with cows (Young, 1977). In our study, the feeding protocol (steady-state regimen) followed before the dilution experiment was composed of $4 \times$ feeding/d on the third day before tracer application, followed by $12 \times$ feeding/d on the second day and on the day of tracer administration. Plots of glucose concentrations presented in Figure 2 are constant over $480 \mathrm{~min}$ of the sampling period post-labeled glucose injection, confirming that the steady-state feeding protocol was the appropriate feeding strategy. Furthermore, in studies with cattle, Putnam et al. (1999) and Schulze et al. (1991) indicated that the low precision of their predictions of glucose production were due to the short duration of their sampling period and low frequency over the later portion of the sampling protocol. In contrast, our model fitted the glucose kinetics curves against the time with high accuracy $(\mathrm{r}=0.91)$. However, the inability of the model to accurately describe overall glucose kinetics following labeled glucose injection was not a problem of the nature of the constructed model, but rather the simultaneous infusion of labeled propionate into the rumen and the labeled glucose into the jugular vein. Due to the simultaneous administration of labeled propionate and labeled glucose, higher initial concentrations were observed (the input of ${ }^{13} \mathrm{C}$ into glucose pools were coming from labeled propionate as well as labeled glucose); thus, the higher intercept of 


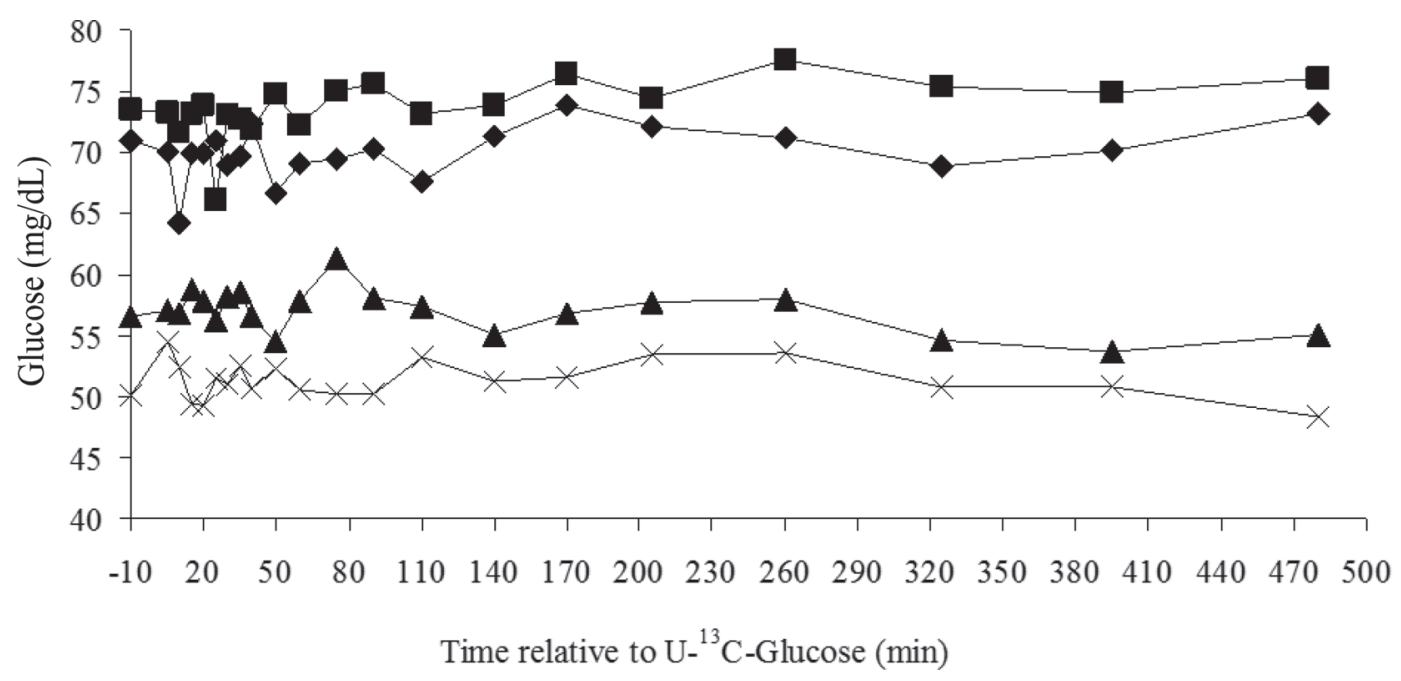

Figure 2. Plasma glucose concentrations over 480 min after $\mathrm{U}_{-}{ }^{13} \mathrm{C}$-glucose injection. $\bullet=$ mean glucose concentration in cows supplemented with monensin prepartum; $=$ mean glucose concentration in control cows prepartum; $\boldsymbol{\Delta}=$ mean glucose concentration in cows supplemented with monensin postpartum; $\times=$ mean glucose concentration in control cows postpartum.

the enrichment glucose kinetic curves against time led to an overestimation of glucose pool sizes because they depended on the intercept of the slope (Figure 3). However, parameters associated with propionate conversion to glucose depended on the slope, which was unaffected by the administration of labeled materials; hence, slope could be used to calculate propionate contribution to gluconeogenesis.

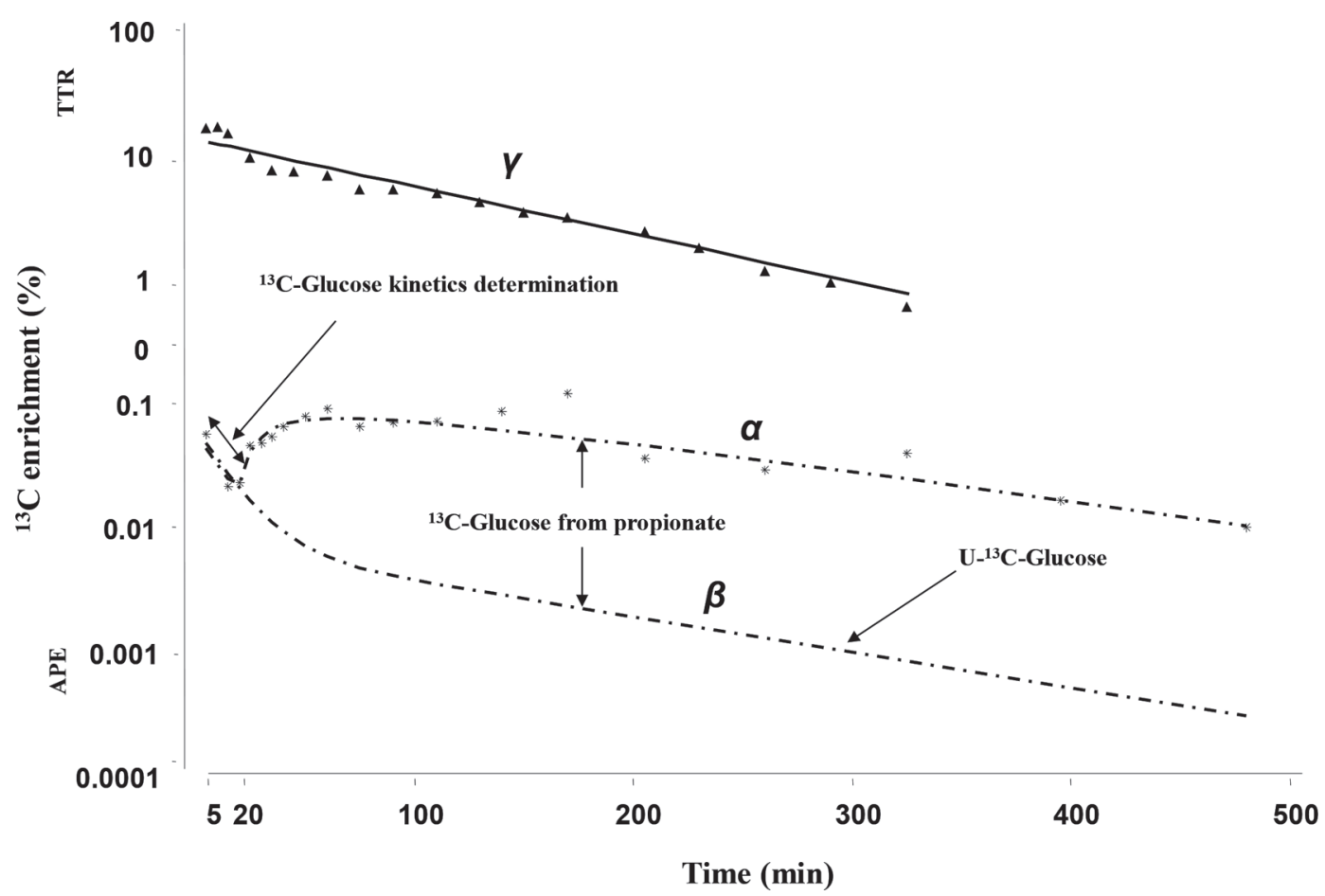

Figure 3. Ruminal propionate and plasma glucose kinetics in transition dairy cows. Curve $\alpha$ represents the best fit of ${ }^{13} \mathrm{C}$-glucose observed $\left.{ }^{*}\right)$ enrichment values. Curve $\beta$ simulates the theoretical ${ }^{13} \mathrm{C}$-glucose kinetics over the time following a single injection of $\mathrm{U}-{ }^{13} \mathrm{C}$-glucose into the jugular vein. The area between $\alpha$ and $\beta$ represents the ${ }^{13} \mathrm{C}$-glucose enrichment coming from ruminal propionate or propionate conversion to glucose. Curve $\gamma$ represents the best fit of observed $(\boldsymbol{\Lambda})$ propionate enrichment values following single intraruminal infusion of ${ }^{13} \mathrm{C}_{3}$-propionate. $\mathrm{APE}=$ atom percent excess; TTR $=$ tracer to tracee + tracer ratio. 
Fluxes of ${ }^{13} \mathrm{C}$ of the tracers between pools are presented in Table 2, such movements express the fraction of the tracer molecules moving in and out of glucose pools per unit time (min). To the best of our knowledge, very little comparable data exist in the literature examining the effect of monensin on gluconeogenic kinetic parameters during the transition period. As mentioned elsewhere, for the model to fit the data, we added an extra compartment (i.e., DC) between propionate and glucose plasma (GIP). In biological terms, this DC would represent either the liver alone or the liver together with the rumen wall, where propionate could be oxidized before it is recovered in plasma glucose (Kristensen et al., 2000; Kristensen and Harmon, 2004). Propionate is extensively (90-95\%) converted to glucose, primarily in the liver, after it reaches the portal blood (Reynolds et al., 2003). In the present study, ${ }^{13} \mathrm{C}$-propionate flux into the DC averaged $0.1 \% / \mathrm{min}$ and did not change due to monensin supplementation in the diet. The lack of an effect on ${ }^{13} \mathrm{C}$-propionate flux to the DC would indicate that monensin could improve the glucogenic potential of propionate by either increasing its efficiency to produce glucose or increasing its complete oxidation (McCarthy et al., 2015b). The delay time (time of ${ }^{13} \mathrm{C}$ of propionate spent in the DC before it is delivered into GIP) ranged between 12.6 and 17.4 min and was unaffected by MON. We found no comparable data in the literature for the delay time, but it appears that the time spent by the liver to metabolize propionate did not change with MON either prepartum or postpartum.

Sources that contribute to the glucose pool include ruminal propionate, starches that escape ruminal fermentation, and some glucose (less than $10 \%$ of total energy absorption; Young, 1977) absorbed from the small intestine. In general, monensin has been shown to change the site of digestion of carbohydrate fractions (McGuffey et al., 2001), decrease fiber digestibility (Haimoud et al., 1995), but have no overall effect on OM digestibility (McCarthy et al., 2015a). Monensin increased fiber as well as apparent gross energy digestibility in prepartum dairy cows (Plaizier et al., 2000): intake was similar to the intake of our cows during the kinetic experiment. The rate of ${ }^{13} \mathrm{C}$-glucose that irreversibly left the plasma pool (fractional catabolic rate in GlP) was reduced by $61.5 \%$ (Table 2) in prepartum cows provided MON, even at an intake of $11.4 \mathrm{~kg}$ of $\mathrm{DM} / \mathrm{d}$, which was significantly lower than for CON cows. Results of our study may indicate that the inclusion of monensin in the diet provided some of the glucose carbons used to meet the energy needs of the cow prepartum. Such an assumption is supported by the moderate level of fatty acids $(228 \mathrm{mEq} / \mathrm{L})$ prepartum in MON cows, which may have reduced catabolism of
${ }^{13} \mathrm{C}$-glucose molecules from plasma glucose. Conversely, in the study of Arieli et al. (2001), no change in DMI occurred with the inclusion of monensin in the diet, leading to the conclusion that DMI was the driving factor for meeting the energy demands of the cows close to parturition. The increase in intake to $20 \mathrm{~kg}$ of $\mathrm{DM} / \mathrm{d}$ on d 19 after parturition likely supplied most of the cow's energy needs.

Glucose concentration, as predicted by the model, ranged from 104 to $144 \mathrm{mg} / \mathrm{dL}$ for the period from injection to $480 \mathrm{~min}$ postinjection. These values are higher than weekly glucose concentrations, which ranged between 52 and $69 \mathrm{mg} / \mathrm{dL}$ from d -30 to 56 relative to parturition; these weekly glucose concentrations are in line with values reported in the literature (Karcher et al., 2007; McCarthy et al., 2015b). The difference between the model-calculated values for glucose concentration and the mean weekly glucose concentrations could be attributed to the concurrent administration of labeled propionate and labeled glucose, which increased the y-intercept of the enrichment kinetics curves used to calculate glucose concentration leading to an overestimation of the concentration (Figure 3). Although the absolute values of glucose concentrations were overestimated, the additive effect of labeled propionate and labeled glucose did not adversely affect the accuracy of the prediction. Indeed, the small FSD for the prediction of glucose concentration during the best fit of glucose enrichment kinetic curves averaged $4.0 \%$ (range 2.7 to $5.0 \%$ ) which ensures that the statistical uncertainty for the prediction is minimized (Wastney et al., 1999; Stefanovski et al., 2003).

Plasma glucose kinetic estimations were assumed to satisfy the 2-pool criterion. In other words, the assumption was made that ${ }^{13} \mathrm{C}$ from exogenously injected labeled glucose was distributed between 2 pools in the body: the plasma glucose (GlP), which corresponded to the initial distribution space, and the secondary glucose (GlS), which is a putative glucose pool that rapidly exchanges labeled glucose with the plasma glucose (Arieli et al., 2001). The size of this pool was estimated based on fluxes between glucose pools and the mass of the GlP. Overall glucose kinetics solution of the model were based on the assumption that glucose labels are distributed between GIP and GlS. The nature of the GlS pool is unknown; it may represent only a small fraction (20\%) of liver glycogen (Arieli et al., 2001), but glucose is predominately coming from lactate (Larsen and Kristensen, 2013). The liver has an increased affinity in mobilizing L-lactate to produce glucose in transition cows (Larsen and Kristensen, 2012); thus, it can be assumed that, under the current experimental conditions, during the 8-h sampling period, a large fraction of lactate was mobilized, resulting in a decrease in GlS. 
The absolute values of glucose distribution space and glucose pools varied from what has been reported in the literature (Putnam et al., 1999; Arieli et al., 2001). Part of the variation is due to the additive effect of the concurrent administration of labeled propionate and labeled glucose, and to the high standard error of the glucose enrichment data for individual cows. The error was caused because, in some cows, there was a fluctuation pattern of observed enrichment versus the predicted values by the model (data not shown). Consequently, the data points that deviated from the ideal steadystate pattern were omitted from the model, resulting in a reduction of the accuracy of the calculated glucose pools. However, a qualitative evaluation of the pools indicated a positive effect of MON on GIP and the glucose distribution space, which increased by $25.7 \% / \mathrm{kg}$ of $\mathrm{BW}$, on average, during the kinetic experiment before parturition. However, glucose pools were reduced with MON after parturition.

The increase in glucose entry rate without an apparent change in plasma glucose concentration, but with an increase in glucose distribution space and GIP and a decrease in GlS, might suggest increased uptake of glucose by peripheral tissues such as fetus in late gestation and mammary gland in early lactation in response to monensin (Stephenson et al., 1997; Mullins et al., 2012). In fact, the reduction in fractional catabolic rate (Table 2) of glucose in plasma without changing plasma glucose concentration suggests that plasma glucose concentration is a poor proxy for gluconeogenic flux and glucose turnover (Mullins et al., 2012).

The majority of quantitative studies of gluconeogenesis involve intraruminal infusion of ${ }^{14} \mathrm{C}$ - or ${ }^{13} \mathrm{C}$ propionate followed by the isolation and analysis of glucose (Annison and Bryden, 1999). Published reports in dairy cows have shown that propionate forms 46 to $78 \%$ of net liver glucose release (Larsen and Kristensen, 2013) Almost $95 \%$ of portal flux of propionate is available to the liver for gluconeogenesis (Reynolds et al., 2003 ), of which $94 \%$ is removed by the liver of cattle (Casse et al., 1994). Depending on the energy status of the cow, propionate may pass through the tricarboxylic acid (TCA) cycle, which results in the transfer of labeled $\mathrm{C}$ into $\mathrm{CO}_{2}$ (respiratory pathway) or be converted to glucose (gluconeogenic pathway; Brockman, 2005). In the conversion of propionate to phosphoenolpyruvate via oxaloacetate, the common intermediate with respiratory pathway, pyruvate through acetyl-CoA is metabolized to $\mathrm{CO}_{2}$. In this case, a crossover of labeled molecules between the 2 pathways (respiration and gluconeogenesis) results in a loss of labeled molecules from one pathway to the other without a net loss of nonlabeled molecules (Brockman, 2005), leading to an underestimation of the glucogenic potential of the pre- cursor by 15 to $20 \%$ (Lindsay, 1978). To account for the lost radioactivity (labeled $\mathrm{C}$ recycling) of propionate carbons during the process of gluconeogenesis, Wiltrout and Satter (1972) used $2{ }^{14}$ C-propionate in lactating dairy cows to apply a fixed partition factor equal to 1.35. Their calculations suggested that propionate contributed to a maximum of $60 \%$ of the total blood glucose entry in lactating cows (32 and $45 \%$ minimum values did not take into account the label $\mathrm{C}$ recycling in the TCA cycle for nonlactating and lactating cows, respectively). Another potential area that affects the estimations of gluconeogenesis from propionate is its oxidation within the rumen wall. Unlike sheep, where an extensive (60-80\%) incorporation of $\mathrm{C}$ from propionate to lactate occurs before conversion to glucose (Perry et al., 1994), a negligible (about 3-5\%) oxidation of propionate occurs within the rumen epithelium of cows (Bergman, 1990). This is in agreement with the results of Brockman (2005), who indicated that in the movement of $\mathrm{C}$ label from glucose to pyruvate or lactate and back to glucose, the exit of the $\mathrm{C}$ label was not detected. The nature of our model did not allow estimations of incorporated VFA into the microbial mass in the rumen, and also estimations of solid stores of glucose such as intracellular glycogen. According to Noziere et al. (2003), who estimated propionate sequestration in the rumen, microbial uptake of propionate is $10.3 \%$. It is then obvious that our estimate of net propionate production (rumen net production rate of propionate; Table 3) was likely overestimated by the same amount. Coupled with the 3 to 5\% (Bergman, 1990; Young, 1977) of ruminal propionate that is oxidized to lactate within the rumen wall, the propionate originated gluconeogenesis in the liver should then be overestimated by almost $15.5 \%$. This could lead to an underestimation of gluconeogenic parameters, namely PrIGl, PrContrGl, and PrConvGl. Therefore, values of PrIGl, PrContrGl, and PrConvGl presented in Table 3 are corrected by a factor of 1.55 to account for the crossover of $\mathrm{C}$ into the TCA cycle, oxidation of propionate within the rumen wall, and the sequestration of propionate.

Values for gluconeogenic parameters presented in Table 3 are similar to what has been reported in the literature. Although information with respect to propionate-mediated gluconeogenesis in dairy cows has been examined extensively, limited information exists on the effect of monensin on the gluconeogenic potential of propionate during the transition period.

Plasma GDR was comparable to the outflux rate of glucose from the plasma glucose pool in the study of Arieli et al. (2001). According to Herbein et al. (1978), GDR represents the net quantity being used per unit time, or the net quantity of glucose that must be syn- 
thesized (gluconeogenesis) or absorbed from the tissues per unit of time; likewise, it could also be referred to as the glucose utilization rate.

The liver is the primary site for gluconeogenesis. Monensin could affect gluconeogenesis either by increasing the gluconeogenic flux of propionate or by altering gluconeogenic enzyme capacity in the liver (Karcher et al., 2007). In transition cows, gluconeogenesis might not depend on changes in substrate availability (Markantonatos et al., 2009), but rather the capacity of the liver to express hepatic enzymes (Mullins et al., 2012). It could also be speculated that the postpartum increase in liver metabolism of fatty acids has negative effects on liver uptake of propionate (Larsen and Kristensen, 2013). Glucose disposal rate was reduced due to monensin inclusion in the diet and was significant $(P=$ 0.01) postpartum. Comparisons of the mean values of the glucose utilization rate suggested that MON and the reproductive stage as well as the interaction of the treatment $\times$ reproductive stage $(P<0.001, P<$ 0.0001 , and $P<0.01$, respectively) lowered the glucose utilization rate by $55 \%$ on average (Table 3). These results confirmed those reported by Arieli et al. (2001), who also found a reduction in glucose utilization with monensin. In a recent study, when monensin was administered in multiparous cows fed a high-starch diet from $\mathrm{d} 1$ to 21 postpartum, the propensity of the liver to convert glucose to propionate tended to increase (McCarthy et al., 2015b); however, any increase in glucose was associated with an increase input of propionate in the liver. In another study (McCarthy et al., 2015c), the research concluded that the capacity of the liver to convert $1-{ }^{14} \mathrm{C}$-propionate to $\mathrm{CO}_{2}$ was 127 and $83 \%$ of prepartum values on d 1 and 21, respectively. However, these values were almost in equilibrium with the capacity of the liver to convert propionate to glucose, which was 126 and $85 \%$ of prepartum values on $\mathrm{d} 1$ and 21 postpartum. Thus, the amount of propionate converted to glucose was almost equal to the amount of glucose available for oxidation. Those results do not document that propionate efficiency for gluconeogenesis improves; this is because the increase in the ratio of glucose to $\mathrm{CO}_{2}$ is a result of the increased availability of the substrate (propionate). In contrast, although we did not actually measure the ratio of glucose to $\mathrm{CO}_{2}$ in the blood, our GDR values indicated that the catabolism of glucose (Herbein et al., 1978) was decreased by $55 \%$ with MON, although propionate delivered to the liver did not change (Table 3). It appears that, in the earlylactation cow, the liver has a propensity to convert propionate to glucose rather than oxidize it (Drackley et al., 2001). That would explain why PrContrGl was increased even though the PrConvGl was unaffected by the treatment.
As a cow transitions from late gestation to early lactation, the liver should adapt to a situation where the DMI is not linearly correlated with enhanced energy demands to support the onset of the lactation (Bell, 1995). The liver net uptake of propionate increases from prepartum to postpartum and continues to increase as feed intake increases (Larsen and Kristensen, 2009b; Raun and Kristensen, 2011; Larsen and Kristensen, 2012). Despite that, the immediate postpartum increase in propionate supply is insufficient to support the increased liver release of glucose, and hence the liver release of glucose seems to be relatively more dependent on lactate in the immediate postpartum period (Larsen and Kristensen, 2012). Glucogenic precursors via pyruvate show an increased affinity of the liver for lactate in the immediate postpartum period (Reynolds et al., 2003). Indeed, experiments using periparturient dairy cows from $d-9$ to 21 relative to parturition suggested that the uptake of lactate by the liver ranged from 146 to $268 \%$ of the amount released from the portal drain viscera (Reynolds et al., 2003). In contrast, AA are not the preferred source for gluconeogenesis by the liver periparturient (Larsen and Kristensen, 2013). In our study, the glucose input rate into plasma glucose from sources other than propionate did not increase with MON either prepartum or postpartum. During the prepartum period, higher insulin levels with MON may have allowed more propionate for gluconeogenesis in place of other sources; however, postpartum, where insulin resistance is more profound (Drackley et al., 2001), the reduction in glucose inputs from sources other than propionate is difficult to explain. Presumably, insulin resistance in our cows during the postpartum period was not the primary regulatory mechanism of gluconeogenesis.

In our study, as well as the study by Arieli et al. (2001), fatty acid concentrations were moderate and decreased around parturition ( -1 to $1 \mathrm{wk}$ relative to parturition) in cows provided $300 \mathrm{mg}$ of monensin per day. The reduction in fatty acids should indicate that monensin either decreased adipose tissue depletion or increased the hepatic uptake of fatty acids to be further oxidized (Drackley, 1999). However, the level of fatty acids coupled with no increase in milk production should indicate that monensin decreased the demand for glucose rather than decreased its supply.

\section{CONCLUSIONS}

Our model describes and integrates ruminal propionate and blood glucose kinetics, resulting in quantification of propionate and glucose metabolism. Compartmental analysis of propionate and glucose kinetics under the experimental conditions in our study suggests 
that monensin may improve the metabolic status of the transition cow in a way other than by increasing propionate availability. Our results demonstrate that monensin increases the efficiency of gluconeogenesis by (1) increasing propionate contribution to plasma glucose and (2) decreasing glucose input rates from sources other than propionate (i.e., dietary starches, lactate). The reduction in GDR in response to monensin indicates an improved efficiency of glucose utilization by body tissues in transition cows.

\section{ACNOWLEDGMENTS}

The authors sincerely appreciate and gratefully acknowledge Elanco Animal Health for kindly providing stable isotopes and for analyzing VFA and blood samples through a GC-MSD at their facilities in Greenfield, Indiana.

\section{REFERENCES}

Annison, E. F., and W. L. Bryden. 1999. Perspectives on ruminant nutrition and metabolism. II. Metabolism in ruminant tissues. Nutr. Res. Rev. 12:147-177.

AOAC International. 2005. Official Method of Analysis. 18th ed AOAC International, Arlington, VA.

Arieli, A., J. E. Vallimont, Y. Aharoni, and G. A. Varga. 2001. Monensin and growth hormone effects on glucose metabolism in the prepartum cow. J. Dairy Sci. 84:2770-2776.

Armentano, L. E., S. E. Mills, G. Deboer, and J. W. Young. 1984. Effects of feeding frequency on glucose-concentration, glucose-turnover, and insulin concentration in steers. J. Dairy Sci. 67:14451451.

Armentano, L. E., and J. W. Young. 1983. Production and metabolism of volatile fatty-acids, glucose and $\mathrm{CO}_{2}$ in steers and the effects of monensin on volatile fatty-acid kinetics. J. Nutr. 113:1265-1277.

Bannink, A., W. J. J. Gerrits, J. France, and J. Dijkstra. 2011. Variation in rumen fermentation and the rumen wall during the transition period in dairy cows. Anim. Feed Sci. Technol. 172:80-94.

Bell, A. W. 1995. Regulation of organic nutrient metabolism during transition from late pregnancy to early lactation. J. Anim. Sci. 73:2804-2819

Bergman, E. N. 1990. Energy contributions of volatile fatty-acids from the gastrointestinal tract in various species. Physiol. Rev. 70:567-590.

Bergman, E. N., R. S. Reid, M. G. Murray, J. M. Brockway, and F. G. Whitelaw. 1965. Interconversions and production of volatile fatty acids in sheep rumen. Biochem. J. 97:53-58.

Breves, G., E. Schulze, H. P. Sallmann, and D. Gadeken. 1993. The application of 13C-labelled short chain fatty acids to measure acetate and propionate production rates in the large intestines. Studies in a pig model. Z. Gastroenterol. 31:179-182.

Brockman, R. P. 2005. Glucose and short-chain fatty acid metabolism. Pages 291-310 in Quantitative Aspects of Ruminant Nutrition and Metabolism. J. Dijkstra, J. M. Forbes, and J. France, ed. CABI, Wallingford, UK.

Casse, E. A., H. Rulquin, and G. B. Huntington. 1994. Effect of mesenteric vein infusion of propionate on splanchnic metabolism in primiparous Holstein cows. J. Dairy Sci. 77:3296-3303.

Christensen, J. O., R. R. Grummer, F. E. Rasmussen, and S. J. Bertics. 1997. Effect of method of delivery of propylene glycol on plasma metabolites of feed-restricted cattle. J. Dairy Sci. 80:563-568.

Drackley, J. K. 1999. Biology of dairy cows during the transition period: The final frontier? J. Dairy Sci. 82:2259-2273.
Drackley, J. K., T. R. Overton, and G. N. Douglas. 2001. Adaptations of glucose and long-chain fatty acid metabolism in liver of dairy cows during the periparturient period. J. Dairy Sci. 84:E100-E112.

Duffield, T. F., D. Sandals, K. E. Leslie, K. Lissemore, B. W. McBride, J. H. Lumsden, P. Dick, and R. Bagg. 1998. Effect of prepartum administration of monensin in a controlled-release capsule on postpartum energy indicators in lactating dairy cows. J. Dairy Sci. 81:2354-2361.

France, J., and J. Dijkstra. 2005. Volatile fatty acid production. Pages 157-175 in Quantitative Aspects of Ruminant Digestion and Metabolism. J. Dijkstra, J. M. Forbes, and J. France, ed. CABI, Wallingford, UK.

Grummer, R. R. 1995. Impact of changes in organic nutrient metabolism on feeding the transition dairy cow. J. Anim. Sci. 73:28202833.

Haimoud, D. A., M. Vernay, C. Bayourthe, and R. Moncoulon. 1995. Avoparcin and monensin effects on the digestion of nutrients in dairy cows fed a mixed diet. Can. J. Anim. Sci. 75:379-385.

Herbein, J. H., R. W. Vanmaanen, A. D. Mcgilliard, and J. W. Young. 1978. Rumen propionate and blood-glucose kinetics in growing cattle fed isoenergetic diets. J. Nutr. 108:994-1001.

Karcher, E. L., M. M. Pickett, G. A. Varga, and S. S. Donkin. 2007 Effect of dietary carbohydrate and monensin on expression of gluconeogenic enzymes in liver of transition dairy cows. J. Anim. Sci. 85:690-699.

Kristensen, N. B., G. Gabel, S. G. Pierzynowski, and A. Danfaer. 2000. Portal recovery of short-chain fatty acids infused into the temporarily-isolated and washed reticulo-rumen of sheep. Br. J. Nutr. 84:477-482.

Kristensen, N. B., and D. L. Harmon. 2004. Splanchnic metabolism of volatile fatty acids absorbed from the washed reticulorumen of steers. J. Anim. Sci. 82:2033-2042.

Larsen, M., and N. B. Kristensen. 2009a. Effect of abomasal glucose infusion on splanchnic and whole-body glucose metabolism in periparturient dairy cows. J. Dairy Sci. 92:1071-1083.

Larsen, M., and N. B. Kristensen. 2009b. Effect of abomasal glucose infusion on splanchnic amino acid metabolism in periparturient dairy cows. J. Dairy Sci. 92:3306-3318.

Larsen, M., and N. B. Kristensen. 2012. Effects of glucogenic and ketogenic feeding strategies on splanchnic glucose and amino acid metabolism in postpartum transition Holstein cows. J. Dairy Sci. 95:5946-5960

Larsen, M., and N. B. Kristensen. 2013. Precursors for liver gluconeogenesis in periparturient dairy cows. Animal 7:1640-1650.

Leng, R. A. 1970. Glucose synthesis in ruminants. Adv. Vet. Sci. Comp. Med. 14:209-260.

Leng, R. A., and D. J. Brett. 1966. Simultaneous measurements of the rates of production of acetic, propionic and butyric acids in the rumen of sheep on different diets and the correlation between production rates and concentrations of these acids in the rumen. Br. J. Nutr. 20:541-552.

Leng, R. A., and G. J. Leonard. 1965. Measurement of rates of production of acetic propionic and butyric acids in rumen of sheep. Br. J. Nutr. 19:469-484.

Lindsay, D. B. 1978. Gluconeogenesis in ruminants. Biochem. Soc. Trans. 6:1152-1156.

Littell, R. C., G. A. Milliken, W. W. Stroup, and R. D. Wolfinger. 1996. SAS System for Mixed Models. SAS Institute Inc., Cary, NC.

Markantonatos, X., Y. Aharoni, L. F. Richardson, and G. A. Varga. 2009. Effects of monensin on volatile fatty acid metabolism in periparturient dairy cows using compartmental analysis. Anim. Feed Sci. Technol. 153:11-27.

Martin, C., N. B. Kristensen, and P. Huhtanen. 2001. Comparison of non-tracer and tracer methods for determination of volatile fatty acid production rate in the rumen of sheep fed on two levels of intake. Br. J. Nutr. 86:331-340.

McCarthy, M. M., M. S. Piepenbrink, and T. R. Overton. 2015c. Associations between hepatic metabolism of propionate and palmitate in liver slices from transition dairy cows. J. Dairy Sci. 98:70157024 . 
McCarthy, M. M., T. Yasui, C. M. Ryan, G. D. Mechor, and T. R. Overton. 2015a. Performance of early-lactation dairy cows as affected by dietary starch and monensin supplementation. J. Dairy Sci. 98:3335-3350.

McCarthy, M. M., T. Yasui, C. M. Ryan, S. H. Pelton, G. D. Mechor, and T. R. Overton. 2015b. Metabolism of early-lactation dairy cows as affected by dietary starch and monensin supplementation. J. Dairy Sci. 98:3351-3365.

McGuffey, R. K., L. F. Richardson, and J. I. D. Wilkinson. 2001. Ionophores for dairy cattle: Current status and future outlook. J. Dairy Sci. 84:E194-E203.

Mullins, C. R., L. K. Mamedova, M. J. Brouk, C. E. Moor, H. B. Green, K. L. Perfield, J. F. Smith, J. P. Harner, and B. J. Bradford. 2012. Effects of monensin on metabolic parameters, feeding behavior, and productivity of transition dairy cows. J. Dairy Sci. 95:1323-1336.

Nielsen, N. I., and K. L. Ingvartsen. 2004. Propylene glycol for dairy cows: A review of the metabolism of propylene glycol and its effects on physiological parameters, feed intake, milk production and risk of ketosis. Anim. Feed Sci. Technol. 115:191-213.

Nolan, J. V., R. A. Leng, R. Dobos, and R. C. Boston. 2014. The production of acetate, propionate and butyrate, in the rumen of sheep: fitting models to $14 \mathrm{C}$ - or $13 \mathrm{C}$-labelled tracer data to determine synthesis rates and interconversions. Anim. Prod. Sci. 54:2082-2088

Noziere, P., S. Gachon, and M. Doreau. 2003. Propionate uptake by rumen microorganisms: The effect of ruminal infusion. Anim. Res. 52:413-426.

NRC. 2001. Nutrient Requirements of Dairy Cattle. 7th rev. ed. Natl. Acad. Sci., Washington, DC.

Ospina, P. A., D. V. Nydam, T. Stokol, and T. R. Overton. 2010. Association between the proportion of sampled transition cows with increased nonesterified fatty acids and beta-hydroxybutyrate and disease incidence, pregnancy rate, and milk production at the herd level. J. Dairy Sci. 93:3595-3601.

Perry, K. W., A. N. Janes, T. E. C. Weekes, D. S. Parker, and D. G. Armstrong. 1994. Glucose and L-lactate metabolism in pregnant and in lactating ewes fed barley- or ground maize-based diets. Exp. Physiol. 79:35-46.

Plaizier, J. C., A. Martin, T. Duffield, R. Bagg, P. Dick, and B. W. McBride. 2000. Effect of a prepartum administration of monensin in a controlled-release capsule on apparent digestibilities and nitrogen utilization in transition dairy cows. J. Dairy Sci. 83:2918-2925.

Putnam, D. E., G. A. Varga, and M. H. Green. 1999. Glucose kinetic responses to protein supplementation and exogenous somatotropin in late gestation dairy cows. J. Dairy Sci. 82:1274-1281.

Rabelo, E., R. L. Rezende, S. J. Bertics, and R. R. Grummer. 2005. Effects of pre- and postfresh transition diets varying in dietary energy density on metabolic status of periparturient dairy cows. J. Dairy Sci. 88:4375-4383.
Raun, B. M. L., and N. B. Kristensen. 2011. Metabolic effects of feeding ethanol or propanol to postpartum transition Holstein cows. J. Dairy Sci. 94:2566-2580.

Reynolds, C. K., P. C. Aikman, B. Lupoli, D. J. Humphries, and D. E. Beever. 2003. Splanchnic metabolism of dairy cows during the transition from late gestation through early lactation. J. Dairy Sci. $86: 1201-1217$

Roe, M. B., C. J. Sniffen, and L. E. Chase. 1990. Techniques for measuring protein fractions in feedstuffs. Pages 81-88 in Proc. Cornell Nutr. Conf. Feed Manuf. Cornell University, Ithaca, NY.

Schulze, E., H. Fuhrmann, E. S. Neitzel, W. W. Giese, and H. P. Sallmann. 1991. Glucose entry rate in dairy-cattle as determined by stable isotope C-13-labeled glucose at different stages of reproduction. Comp. Biochem. Physiol. B 100:167-171.

Seal, C. J., and D. S. Parker. 1994. Effect of intraruminal propionic acid infusion on metabolism of mesenteric-drained and portaldrained viscera in growing steers fed a forage diet. 1. Volatile fatty acids, glucose, and lactate. J. Anim. Sci. 72:1325-1334.

Stefanovski, D., P. J. Moate, and R. C. Boston. 2003. WinSAAM: A windows-based compartmental modeling system. Metabolism 52:1153-1166.

Stephenson, K. A., I. J. Lean, M. L. Hyde, M. A. Curtis, J. K. Garvin, and L. B. Lowe. 1997. Effects of monensin on the metabolism of periparturient dairy cows. J. Dairy Sci. 80:830-837.

Van Maanen, R. W., J. H. Herbein, A. D. McGilliard, and J. W. Young. 1978. Effects of monensin on in vivo rumen propionate production and blood glucose kinetics in cattle. J. Nutr. 108:10021007.

Van Soest, P. J., J. B. Robertson, and B. A. Lewis. 1991. Methods for dietary fibre, neutral detergent fibre and non-starch polysaccharides in relation to animal nutrition. J. Dairy Sci. 74:3583-3597.

Wastney, M. E., B. H. Patterson, O. A. Linares, P. C. Greif, and R. C. Boston. 1999. Investigating Biological Systems Using Modeling: Strategies and Software. Academic Press, San Diego, CA.

White, R. G., J. W. Steel, R. A. Leng, and J. R. Luick. 1969. Evaluation of three isotope-dilution techniques for studying kinetics of glucose metabolism in sheep. Biochem. J. 114:203-214.

Wildman, E. E., G. M. Jones, P. E. Wagner, R. L. Boman, H. F. Troutt, and T. N. Lesch. 1982. A dairy cow body condition scoring system and its relationship to selected production characteristics. J. Dairy Sci. 65:495-501

Wiltrout, D. W., and L. D. Satter. 1972. Contribution of propionate to glucose synthesis in lactating and non-lactating cow. J. Dairy Sci. 55:307-317.

Wolfe, R. R. 1992. Radioactive and Stable Isotope Tracers in Biomedicine: Principles and Practice of Kinetic Analysis. Wiley-Liss, New York, NY.

Young, J. W. 1977. Gluconeogenesis in cattle: Significance and methodology. J. Dairy Sci. 60:1-15. 